\title{
INFLUENCE OF CNT-NANOPARTICLES IN THE FILTRATE CHARACTERISTICS AND FILTER CAKE FORMATION OF A WATER-BASED DRILLING FLUID
}

\author{
Anoop Kanjirakat ${ }^{* 1}$, Arnel Carvero ${ }^{2}$, Reza Sadr $^{3}$, Mahmood Amani $^{3}$ \\ ${ }^{1}$ Mechanical Engineering Program, Texas A\&M University at Qatar, Doha, Qatar \\ ${ }^{2}$ Petroleum Engineering Program, Texas A\&M University at Qatar, Doha, Qatar \\ ${ }^{3}$ J. Mike Walker '66 Department of Mechanical Engineering, Texas A\&M University, College Station, USA
}

\begin{abstract}
In a reservoir drilling application, the drilling mud should minimize the amount of the filtrate fluid entering into the reservoir formation. To ease the drilling process, the filter cake formed should also be thin, stable, and of uniform distribution. The addition of nanoparticles into the drilling mud is expected to improve these functionalities. In the present work, the effect of addition of carbon nanotubes (CNT) into a water-based drilling mud sample in improving its filtrate characteristics is studied. The filtrate volume, dry and wet weights, and thickness of the filter cakes are measured to evaluate the filtrate characteristics. Ceramic disks of two pore-throat sizes are used in the experimentation. The addition of CNT particles is observed to beneficial in reducing the filtrate amount or fluid loss. An increase in nanoparticle loading is observed to have increased the filtrate cake thickness. The porosity of the filter cake formed is observed to be lower than that of the ceramic disk used.
\end{abstract}

KEYWORDS: drilling mud, nanoparticles, filter cake, fluid loss, carbon nanotubes.

\section{INTRODUCTION}

The selection of drilling fluids and the proper control of its solid contents play a significant role in the overall economics of the oil and gas industry. In a drilling process, the drilling fluid assists in drilling boreholes into the earth's surface. It is pumped to the bottom of the borehole to cool and lubricate the drill bit. This fluid also aids removing the rock debris from drilling area and convey it to the surface. Proper selection of the drilling fluid is vital to reduce cost, have a low impact on the environment, and to enhance the production efficiency for a specific well. The viscosity, gel strength, and filtration (or fluid loss control) are among the significant properties that determine the behavior of drilling mud at high-pressure hightemperature (HPHT) drilling applications. Drilling fluid, along with being a cooling agent, should also limit the fluid loss into the formation by forming a layer of solid mud on the walls of the borehole.

There are various types of drilling fluids, namely; pneumatic, water-based mud, oil-based mud, and synthetic-based that are being used in various reservoir fields. Water-Based mud is widely (approximately 80 $\%$ of all wells) used drilling fluid in the oil and gas industry, owing to its environmentally friendly nature [1]. Water-Based mud is mostly composed of water and barite and some ingredients to control $\mathrm{pH}$ and viscosity. Barite is added to increase and adjust the drilling fluid density. In most drilling conditions (also termed as an over-balanced drilling condition), the drilling mud is kept at a pressure higher than that excreted by the pore fluid in the formation. Under such circumstances, the drilling fluid would invade into the rock formations with a minimal amount of the filtrate entering into the reservoir formation. To achieve this functionality, clay-forming materials (such as bentonite) are added to the drilling fluid. During the drilling process, the solid particles from the drilling mud are deposited on the walls to form a layer of mud cake (also known as filter cake). An ideal filter cake forms a thin, low permeable layer, which minimizes the further intrusion of fluid into the formation, reducing the fluid loss from the drilling mud. The fluid movement into the formation is then controlled by the permeability of the filter cake. However, an uncontrolled buildup of the filter cake could contribute to a surge in pressure creating irreversible damage to the borehole. Hence, the 
control of the filter cake thickness and its properties is vital for an efficient drilling process. The components in the drilling fluid are found to have a significant influence on the filter cake characteristics.

Solids in the drilling fluid consist of particles with varying sizes. During the filter cake formation, bigger particles form the basic structure of the porous medium. Smaller particles migrate and are deposited within the porous structure. With more clay content, a thinner and harder filter cake formation is observed to be formed [2]. The thickness of the cake also depends on the permeability of the formation. A static or a dynamic fluid loss would occur depending on whether the mud is being circulated or not. As formation damage is partly non-reversible and is depended on the nature of the filter cake, it would be highly recommended to prevent it. Improving the properties of the drilling fluid to optimize the filter cake characteristics would be highly beneficial to the deep drilling industry. Several filtration control additives are being tried in the past with the aim of not only controlling the amount of filtrate formed but also to improve the quality of the filter cake formed. Nanoparticle addition to the basemud would be the right choice as it would also improve its rheological characteristics [3-5].

Amanullah et al.[6] suggested adding nanoparticles along with drilling fluids to improve their rheological and fluid loss characteristics. Several studies with nanoparticle-based drilling fluids were conducted in the past. Based on the low-pressure low temperature (LPLT) filtration and rheological tests on nano-sized silica particles into water-based mud samples, Salih et al.[7] observed that minimal concentrations $(0.1-0.3 \mathrm{wt} \%)$ of nanoparticle could enhance the rheological, hydraulic, and filtration properties, making a smart water-based drilling fluid, which could replace oil-based drilling fluids. Srivatsa and Ziaja [8] used silica nanoparticles along with a biopolymer and surfactant blend to reduce the filtrate loss. They also observed that the use of nanoparticles was ideal for shale-drilling application as it could penetrate into the pores of the shale at the same time could act as bridging material, thus strengthening the wellbore. Sedaghatzadeh and Shahbazi [9] investigated the effect of nanoparticle geometry and particle aggregation on the induced formation damage for water-based drilling fluid. Nano-sized, $\mathrm{CaCO} 3, \mathrm{SiO} 2$, and MWCNT (multi-walled carbon nanotubes) particles were considered in the study. Nanoparticles with tubular shapes (MWCNTs) were observed to create highest mud cake quality when compared to spherically shaped particles, thus imparting the lowest level of formation damage. Ismail et al.[10] also observed that the addition of MWCNT particles was better when compared to silica nanoparticle particles for controlling the fluid loss. Needaa et al. [11] added sepiolite nanoparticles to bentonite-based drilling mud to control the filtration loss and rheological properties. The addition of nanoparticles was observed to have improved the stability of the drilling fluids as well as reduced the fluid loss, especially at high temperatures and pressures.

Despite many studies regarding the effect of the nano-additives on the drilling mud performance, the correlation between the formation's porosity and the morphology of the particles has not been reported. Such a vital correlation will have a significant impact on the mud cake and filtrate, and therefore, it is critical to test and evaluate this correlation before actual implementation in the field. An experimental investigation to study the effect of carbon nanotube (CNT) particles in controlling the filtrate and its influence on changing the structure of the filtrate cake is conducted.

\section{METHODOLOGY}

An API (American Petroleum Institute) Fluid Loss Test, which is the standard static filtration study, is used in the present work to investigate the filtrate characteristics of the drilling mud. The Permeable Plugging Tester kept at $250^{\circ} \mathrm{C}$ temperature and at a differential pressure of $1200 \mathrm{psi}$ is used. The porous rock formation is mimicked using a ceramic disk with specified pore size. The schematic depicting the working principle of the apparatus used in the filtration study is shown in Fig.1. The drilling mud sample is passed through a ceramic disk by applying pressure $\left(\mathrm{P}_{1}\right)$ of $1300 \mathrm{psi}$ at the bottom (by a piston) and backpressure of $100 \mathrm{psi}$ (held in the filtrate chamber). The filtrate liquid is collected for a period of two seconds at intervals of 30 seconds, $1 \mathrm{~min}, 5 \mathrm{~min}, 7.5 \mathrm{~min}, 15 \mathrm{~min}$, and 30 minutes. At the end of 30 minutes, the valve located after the ceramic disk is closed and the entire filtrate amount collected and measured. During the entire experimentation process, as the fluid part moves through the porous disk, a filter cake is formed at the bottom part of the ceramic disk. This is carefully extracted after the experimentation, and its thickness is measured. 
The drilling mud is formulated using the components shown in Table 1. The sample has a mud weight of $12.3 \mathrm{ppg}$ (pounds per gallon) when measured using a standard mud balance. One of the significant solid-component in the formulated drilling mud sample is barite. Bentonite is not included in the preparation as it is a fluid loss controlling agent and could affect the filtration results. The particle size distribution of barite particles is measured using a laser diffraction particle size analyzer (Beckman Coulter, LS13 320). For this, the barite particles were dispersed in water at dilute concentration. The size variation based on volume is shown in Fig. 2(a). The particle sizes varied from a mean diameter of $0.5 \mu \mathrm{m}$ to $100 \mu \mathrm{m}$ with the mean diameter estimated at $21 \mu \mathrm{m}$. The nanomud samples (basemud with carbon nanotubes (CNT)) are prepared by adding appropriate amounts (based on weight, henceforth mentioned as wt\%) of CNT particles into the basemud. Commercially procured multi walled-CNT particles ( $>95 \%$ carbon purity, Outer diameter: 5 -

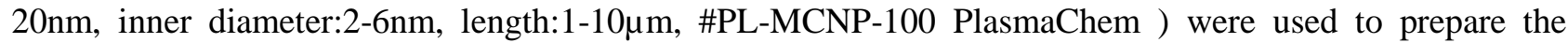
nanoparticle-based mud. A scanning electron microscope image of the CNT particles (as provided by the manufacturer) is shown in Fig 2(b). A stable dispersion is prepared by using ultrasonic vibrations for deagglomerating the particles. An intensified ultrasonication using a probe-type sonicator (QSonica S-4000, 20 $\mathrm{kHz}$ ) is used. The nano-mud suspension was sonicated for 30 minutes. During ultrasonication, the temperature would increase, resulting in some vaporization of water content from the drilling mud. To reduce this effect, the sample was kept in a temperature-controlled bath (maintained at $15^{\circ} \mathrm{C}$ ) while applying sonication. Experiments were conducted immediately after preparing the nanomud sample to avoid the chances of sedimentation. Qualitative observation of the nano-mud samples showed no significant sedimentation of particles in a stationary vessel, even 6 hours after preparation. Filtrate measurements of the basemud $(0 \mathrm{wt} \%)$ and basemud loaded with $1 \mathrm{wt} \%$ and $2 \mathrm{wt} \%$ nanoparticles are reported in the present study.

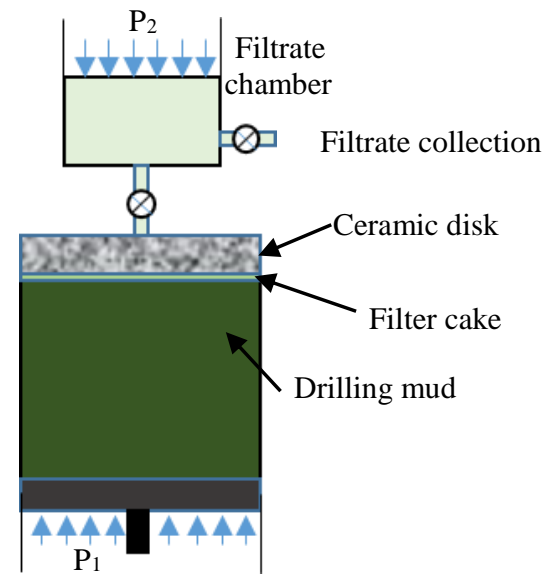

Fig.1 Schematic of the permeable plugging tester used in the filtrate study

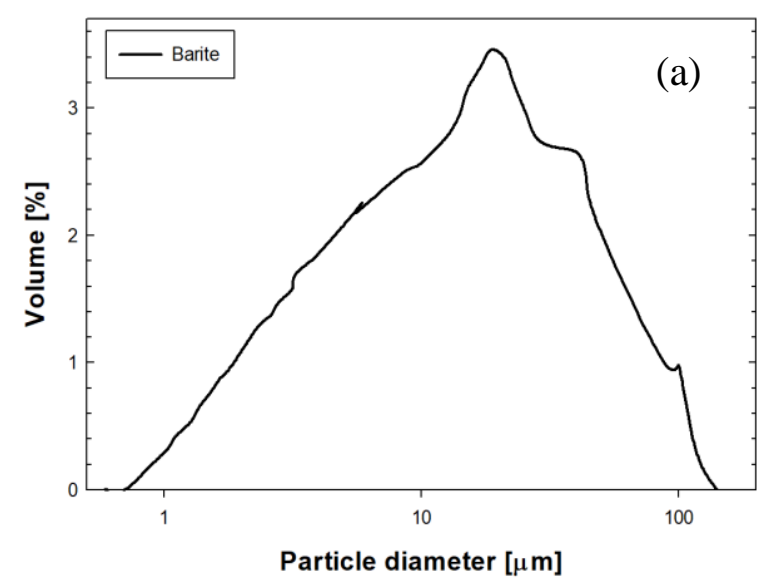

\begin{tabular}{|l|l|}
\hline Components & Mass (g) \\
\hline Water & 266.3 \\
\hline Soda Ash & 0.3 \\
\hline Caustic Soda & 0.3 \\
\hline $\mathrm{NaCl}$ & 108.0 \\
\hline Flowzan & 1.5 \\
\hline Polysal HT & 5.0 \\
\hline Barite & 122.5 \\
\hline
\end{tabular}

Table 1 Chemical components used for preparing the drilling mud (basemud)

Fig. 2 (a) Particle size distribution of barite used in base mud. (b) Scanning electron microscopy (SEM) image of the carbon nanoparticles used in nanomud samples 
Ceramic disks of two pore-sizes are used in the experimentation. The mean pore throat sizes, as specified by the manufacturer (OFI Testing Equipment Inc.), measures $5 \mu \mathrm{m}$ and $10 \mu \mathrm{m}$ using air standards and has Darcy permeability of $750 \mathrm{mD}$ and $2 \mathrm{D}$, respectively. After filtrate experiment/measurement, the ceramic disk is removed, and the thickness of the filter cake formed on the disk is measured. The thickness is measured using a precision Vernier $( \pm 0.02 \mathrm{~mm})$ at three different locations on the cake, to obtain the average value of the cake thickness, after drying the cake with the ceramic disk in the oven . Quantitative measurement of the porosity of the ceramic disks and the filter cake is made by measuring the dry and wet weights. The wet weights are estimated after saturating the disk with pure water. The porosity of the ceramic disks and the filter cakes are calculated using the following equation;

$$
\begin{gathered}
\emptyset=\frac{V_{p}}{V_{b}}=\frac{\text { pore volume }}{\text { bulk volume }} \times 100 \\
\text { pore volume }=\frac{\text { Wet weight }- \text { Dry weight }}{\text { Density of fluid }}
\end{gathered}
$$

where the bulk volume is calculated from the geometrical measurements of the disk and the filter cake.

\section{RESULTS AND DISCUSSION}

The filtrate experiments were conducted following the procedures, as explained earlier. Several experimental trials were conducted prior to actual experimentation to estimate the uncertainty in the filtrate volume collected. At 30 minutes, the maximum uncertainty in the filtrate volume is estimated to be $\pm 5 \mathrm{ml}$.
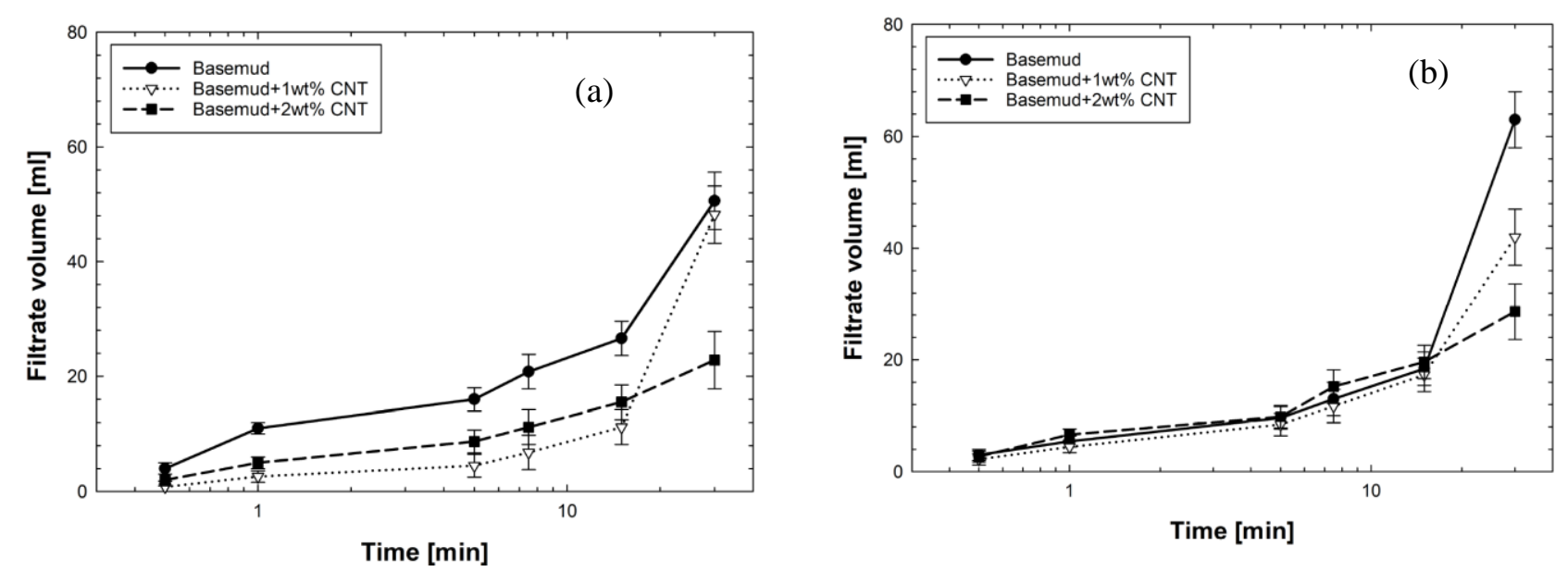

Fig. 3 (a) Filtrate volume collected for $5 \mu \mathrm{m}$ pore size disk. (b) Filtrate volume collected for $10 \mu \mathrm{m}$ pore size disk.

Figure 3 shows the filtrate volume measured for the basemud and basemud loaded with CNT particles while passing them through $5 \mu \mathrm{m}$ and $10 \mu \mathrm{m}$ pore size disks. The filtrate volume collected at different time intervals is plotted here. The filtrate volumes collected at 30 seconds (known as 'spurt') and at 30 minutes ('whole filtrate') are reliable as they are devoid of experimentation errors. From Fig.3, it is observed that, for the basemud, the filtrate volume collected is at least $20 \%$ lower while passing through $5 \mu \mathrm{m}$ pore disk, than while passing through the $10 \mu \mathrm{m}$ pore disk. For both the case, the filtrate volume is observed to be increasing non-linearly with time. In addition, the filtrate volume collected for the basemud is observed to be more than that of the nanomud samples. For the experiments using $5 \mu \mathrm{m}$ pore disk, when compared to nanomud sample with $2 \mathrm{wt} \%$ CNT loading, the nanomud sample with $1 \mathrm{wt} \%$ CNT loading recorded a lower amount of filtrate until 15 minutes. However, at 30 minutes, the $1 \mathrm{wt} \%$ nanomud sample showed higher filtrate volume than the $2 \mathrm{wt} \%$ nanomud suspension. For the experiments with $10 \mu \mathrm{m}$ pore disk, both the nanomud samples and the basemud samples are observed to have similar amounts of filtrate volumes until 15 minutes. At 30 minutes, similar to the observation with $5 \mu \mathrm{m}$ pore disk, filtrate volume shows considerable reduction while using CNT. The filtrate volume is observed to decrease with increasing 
CNT concentration. These trends show the interplay between the nanoparticle sizes, concentration and the porosity of the ceramic disks.

Along with a reduction in the amount of filtrate, an ideal mud sample should also form a thin, uniform, and stable filter cake. Figure 4 shows images of the filter cakes obtained after the experimentation. The thickness of the filter cake together with the disk is measured and is tabulated in Table 2.

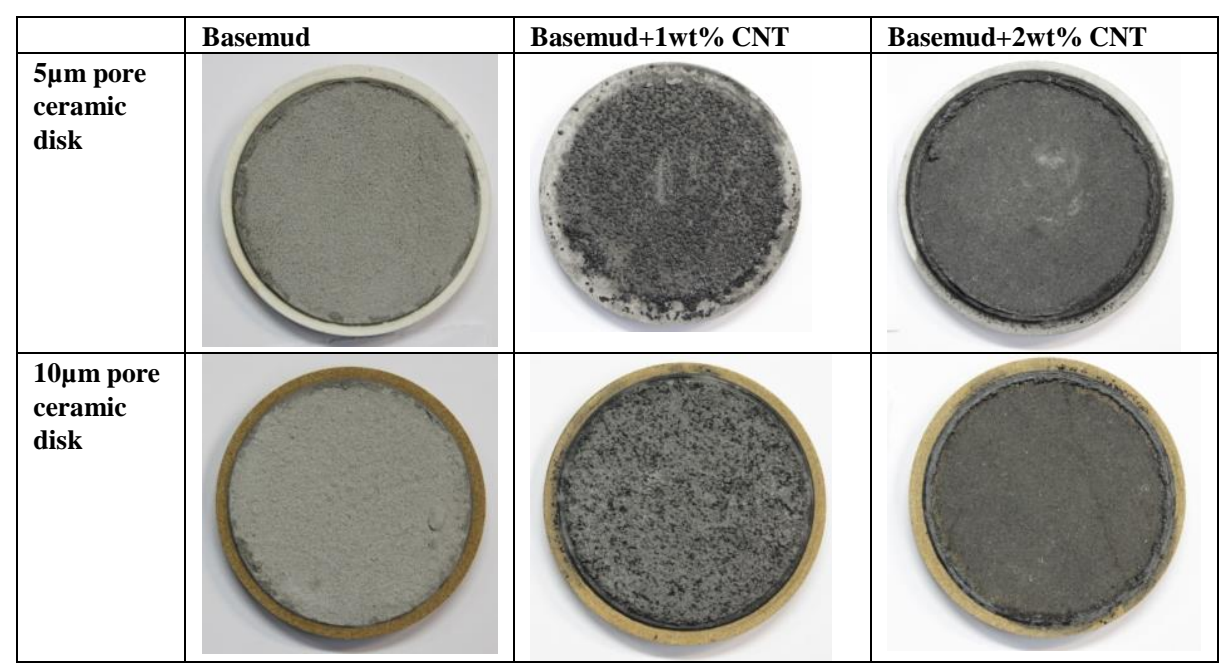

Fig. 4 Images of the filter cake formed by basemud and nanomud samples.

A close observation of the images shows that the basemud made a uniform filter cake while passing though both $5 \mu \mathrm{m}$ and $10 \mu \mathrm{m}$ pore disks. For the $1 \mathrm{wt} \%$ nanomud sample, the filter cake is observed to be more porous and unevenly distributed. The CNT particles are observed to be agglomerated and scattered and throughout the filter cake surface. The filter cake thickness is also observed to be larger than that created by the basemud sample. For the $2 \mathrm{wt} \%$ CNT loading, the filter cake formed on both the disks is observed to be broken. This might be due to the larger built-up of filter cake, which got detached during its retrieval. Hence, the thickness measured for the filter cake for the $2 \mathrm{wt} \%$ loading is unreliable. We have repeated the experiment with $2 \mathrm{wt} \%$ nanomud sample; however, a similar breakage of the filter cake is observed at this high concentration.

From the above observation, it can be inferred that even though $2 \mathrm{wt} \%$ nanomud samples have lower amounts of filtrate, $1 \mathrm{wt} \%$ nanomud samples would be preferred in practical drilling applications as they create better filter cakes.

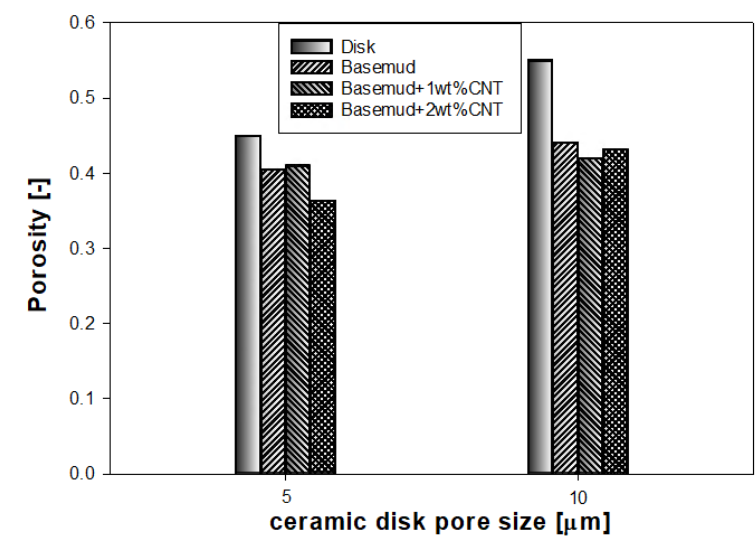

Fig. 5 Porosity values exit mated for the ceramic disk and disks after conducting experiments with basemud and nanomud samples

\begin{tabular}{|l|c|}
\hline $\begin{array}{l}\text { Disks used for different } \\
\text { experiments }\end{array}$ & $\begin{array}{l}\text { Thickness } \\
{[\mathbf{m m}]} \\
\mathbf{\pm 0 . 0 2}\end{array}$ \\
\hline $5 \mu \mathrm{m}$ pore disk blank & 6.12 \\
\hline $5 \mu \mathrm{m}$ pore disk + Basemud & 6.62 \\
\hline $5 \mu \mathrm{m}$ pore disk + 1wt\% Nanomud & 7.53 \\
\hline $5 \mu \mathrm{m}$ pore disk + 2wt\% Nanomud & 6.51 \\
\hline $10 \mu \mathrm{m}$ pore disk blank & 6.18 \\
\hline $10 \mu \mathrm{m}$ pore disk + Basemud & 6.72 \\
\hline $10 \mu \mathrm{m}$ pore disk + 1wt\% Nanomud & 7.78 \\
\hline $10 \mu \mathrm{m}$ pore disk + 2wt\% Nanomud & 6.92 \\
\hline
\end{tabular}

Table 2 Average thickness measured for the ceramic disk and disk with the filter cake on it. 
The porosity values evaluated from the dry and wet weights are plotted in Fig.5. Porosity values of the ceramic disk together with the disks after filtrate experimentation with basemud and nanomud samples are plotted. The porosity value of the $10 \mu \mathrm{m}$ pore disk is obviously seen to be higher than that of the $5 \mu \mathrm{m}$ pore disk. A particular trend in the variation of porosity values for the filter cakes formed by basemud and nanomud samples is not observed. However, it is clearly observed that the porosity values of the filter cakes formed are lower than that of the ceramic disk.

Extensive studies using CT scans and surface SEM images are needed to be performed to characterize and analyze the porous nature of the filter cake. In the future, detailed investigation in this regard, along with extensive experimentation with varying pore-size disks and different types of nanoparticles, will be conducted.

\section{CONCLUSIONS}

The effect of CNT particles in influencing the filtrate characteristics of a water-based mud sample is experimentally investigated The drilling mud with a mud weight of $12.3 \mathrm{ppg}$ is used as the base mud for comparing the results. CNT particles are added to the base mud, and standard fluid loss studies at $250^{\circ} \mathrm{C}$ and differential pressure of 1200 psi are conducted. The CNT particle concentration and the ceramic disk pore sizes are varied. It is observed that the addition of CNT particles reduces the amount of filtrate fluid. The filtrate amount also reduced with increasing nanoparticle concentration. The thickness of the filter cake formed increased with the addition of nanoparticles. However, at higher particle loading ( $2 \mathrm{wt} \%)$, the filter cake is observed to be broken off. Hence, particle loading of $1 \mathrm{wt} \%$ or less is deemed beneficial for practical drilling applications.

\section{ACKNOWLEDGMENT}

This publication was made possible by UREP grant \# 23-082-2-032 from the Qatar National Research Fund (a member of the Qatar Foundation). The statements made herein are solely the responsibility of the authors.

\section{REFERENCES}

[1] C. J. Burke and J. A. Veil, "Synthetic-based drilling fluids have many environmental pluses," Oil and Gas Journal, vol. 93 , no. $48,1995$.

[2] E. Pitoni, D. A. Ballard, and R. M. Kelly, "Changes in Solids Composition of Reservoir Drill in Fluids During Drilling and the Impact on Filter Cake Properties," 1999/1/1/.

[3] K. Anoop, R. Sadr, R. Yrac, and M. Amani, "Rheology of a colloidal suspension of carbon nanotube particles in a waterbased drilling fluid," Powder technology, vol. 342, pp. 585-593, 2019.

[4] M. Al-saba, A. Al Fadhli, A. Marafi, A. Hussain, F. Bander, and M. Al Dushaishi, "Application of Nanoparticles in Improving Rheological Properties of Water Based Drilling Fluids," in SPE Kingdom of Saudi Arabia Annual Technical Symposium and Exhibition, 2018: Society of Petroleum Engineers.

[5] K. Anoop, R. Sadr, R. Yrac, and M. Amani, "High-pressure rheology of alumina-silicone oil nanofluids," Powder Technology, vol. 301, pp. 1025-1031, 2016.

[6] M. Amanullah, M. K. AlArfaj, and Z. A. Al-abdullatif, "Preliminary test results of nano-based drilling fluids for oil and gas field application," in SPE/IADC Drilling Conference and Exhibition, 2011: Society of Petroleum Engineers.

[7] A. Salih, T. Elshehabi, and H. Bilgesu, "Impact of nanomaterials on the rheological and filtration properties of water-based drilling fluids," in SPE Eastern Regional Meeting, 2016: Society of Petroleum Engineers.

[8] J. T. Srivatsa and M. B. Ziaja, "An experimental investigation on use of nanoparticles as fluid loss additives in a surfactant-polymer based drilling fluids," in International Petroleum Technology Conference, 2011: International Petroleum Technology Conference.

[9] M. Sedaghatzadeh, K. Shahbazi, M. Ghazanfari, and G. Zargar, "Experimental investigation of self-repeating effect of different nanoparticles on internal mud cake formation by water-based drilling fluid in directional wells," in IADC/SPE Asia Pacific Drilling Technology Conference, 2016: Society of Petroleum Engineers.

[10] A. R. Ismail, W. Sulaiman, W. Rosli, M. Z. Jaafar, I. Ismail, and E. Sabu Hera, "Nanoparticles Performance as Fluid Loss Additives in Water Based Drilling Fluids," in Materials Science Forum, 2016, vol. 864: Trans Tech Publ, pp. 189-193.

[11] A.-M. Needaa, P. Pourafshary, A.-H. Hamoud, and A. Jamil, "Controlling bentonite-based drilling mud properties using sepiolite nanoparticles," Petroleum Exploration and Development, vol. 43, no. 4, pp. 717-723, 2016. 